\title{
Comparison of Bacterial And Archaeal Microbiome In Two Bioreactors Fed With Cattle Sewage And Corn Biomass
}

\author{
Caterina Agrimonti \\ University of Parma \\ Giovanna Visoli ( $\nabla$ giovanna.visioli@unipr.it) \\ University of Parma https://orcid.org/0000-0001-9712-3223 \\ Graziano Ferrari \\ AVG Consulting Srl via Farini 1 \\ Anna Maria Sanangelantoni \\ University of Parma
}

\section{Research Article}

Keywords: microbial communities, biodigesters, cattle manure, molecular analysis

Posted Date: December 14th, 2021

DOI: https://doi.org/10.21203/rs.3.rs-1050429/v1

License: @ (i) This work is licensed under a Creative Commons Attribution 4.0 International License. Read Full License 


\section{Abstract}

The bacterial and archaeal communities of two biogas producing plants (P1 and P2), associated with a $999 \mathrm{~kW}$ cogeneration unit, both located in North Italy, were analyzed at start up and fully operating phases, by means of various molecular approaches: i) Automated Ribosomal Intergenic Spacer Analysis; ii) cloning and sequencing of PCR amplicons of archaeal genes 16Srrna and mcrA; iii) 16S rDNA high throughput next generation sequencing. P1 and P2 use the same technology and both were fed with cattle manure and corn silage. During the study of P1 also the post digestor (fed with pig manure) was analyzed. The aim of this research was to characterize the bacterial and archaeal community in two very similar plants to profile the core microbiome. The results of this analysis highlighted that the two plants (producing comparable quantities of volatile fatty acids, biogas, and energy) differed in anerobic microbiota (Bacteria and Archaea). Notably the methanogenic community of P1 was dominated by the strict acetoclastic Methanosaeta (Methanothrix) (up to 23.05\%) and the unculturable Candidatus Methanofastidiosum (up to $32.70 \%$ ), while P2 was dominated by the acetoclastic, but more substrate-versatile, Methanosarcina archaeal genus (49.19\%). The data demonstrated that the performances of plants with identical design, in similar operating conditions, yielding comparable amount of biogas (average of $8662 \mathrm{~m}^{3} / \mathrm{day}$ and $7916 \mathrm{~m}^{3} / \mathrm{day}$ respectively for P1 and P2), VFA (1643 mg/L and $1634 \mathrm{mg} / \mathrm{L})$ and energy recovery (23.90-24 MWh/d) depends on the stabilization of an effective and functionally optimized methanogenic community rather than on the species composition

\section{Statement Of Novelty}

Even though many papers have been published about utilization of organic waste for biogas production, the relationships between microbial communities operating in different plants and efficiency of biogas production, is a still opened question. In this work, we have found that bacterial and archaeal species are different also in plants located in the same geographical area, fed with the same substrate (cow manure and corn silage) and operating at the same conditions. However, these differences do not affect the efficiency of biogas production. Interestingly, our results evidenced the role of not well characterized species (i.e. Candidatus methanofastidiosum) in the process, suggesting that other pathways than those so far identified, are involved in biogas production.

\section{Introduction}

In the last years, the biogas production, starting from organic wastes, has been considerably increased to reduce the consumption of fossil fuels and the environmental impact of methane emissions from zoogenic fluids [1]. The biogas produced by anaerobic digestion from such renewable sources is transformed in fuels that can be used for energy production and transport.

Despite the high operating costs of these plants and the necessity of significant financial incentives, the anaerobic digestion (AD) is a well-established technology and remains a fundamental energy source in the emerging market for renewable energy. This is the reason why, in the circular economy perspective, it is considered a key technology on the path to independence from fossil fuels [2,3]. Italy is one of the leading countries in the biogas production where agricultural, landfill, sewage and manure substrates are converted into biogas using AD and into electricity and heat as illustrated by Benato and Macor in 2019 [4].

As many commercial AD facilities suffer from several problems like long start up times or system instability, the optimization of the process is an important deal. The attention, in this regard, had formerly been focused on the evaluation of substrates and the implementation of plants characteristics, but it was soon hypothesized that the efficiency of the plants was more likely dictated by the composition and activity of the microbial communities from the incoming substrates [5]

The overall process of biogas production is due to the complex, synergistic, interaction among four functional guilds performing the different reactions (hydrolysis, acidogenesis, acetogenesis, methanogenesis). Early in the process, microbial enzymes hydrolyse polysaccharides, proteins and fats into sugars, amino acids and fatty acids. These compounds are then converted into volatile fatty acids (VFAs) and alcohols that are further converted into acetic acid, $\mathrm{CO}_{2}$ and hydrogen (Fig.1). Methanogenic microorganisms belonging to the Archaea domain carry out the final step, the production of methane [6, 7]. Acetoclastic and hydrogenotrophic methanogens, transforming acetic acid, $\mathrm{CO}_{2}$ and hydrogen into methane are particularly sensitive to process conditions, like temperature, $\mathrm{pH}$, redox and inhibitors like sulfidrilic acid produced through the reduction of sulphates [8, 9, 10]. The methanogenic Archaea, mostly represented in biodigesters, belong to Methanomicrobiales, Methanosarcinales and Methanococcales orders [11,12]. The process of biogas formation has been thoroughly dissected, however a little number of prokaryotes involved in anaerobic digestion have been so far isolated because many microbial species are not culturable and little is known about their dynamics and interactions. Methods based on DNA analysis demonstrated to be the best way to study $\operatorname{AD}[13,14,15]$. The gene encoding ribosomal 16S RNA in Bacteria and Archaea is the most used target sequence for many molecular techniques, together with intergenic spacer (IGS) between the small (16S) and large (23S) rRNA genes in the

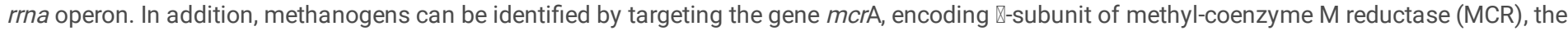
key enzyme involved in final steps of methanogenesis. Unlike other enzymes involved in methanogenic metabolism, MCR is highly specific for methanogens $[16,17]$.

The molecular techniques used for microbiome analysis include ARISA (Automated Ribosomal Intergenic Spacer Analysis) analyzing IGS, clone library sequencing and NGS (Next Generation Sequencing). ARISA, based on the different length of ribosomal intergenic spacers, is a molecular technique for characterizing non-cultivable microbial communities directly from environmental DNA (the whole DNA extracted from samples). It has been widely 
applied for a rapid analysis of biodiversity in large samples, but suffers the limitation of not allowing the recognition, at a taxonomic level, of the species present in the sample [18]. The sequencing of 16Srrna or mcrA genes clone libraries offers a rather precise identification of microorganism but it does not cover the whole microbiome diversity. 16S rDNA NGS is much more exhaustive about the microbiome diversity but is less precise in the identification of microorganisms at species level.

In this study, in order to describe the microbiome evolution in two full-scale biodigesters, managed in the same way, in the different steps of their operation, an integrated approach was followed consisting in i) ARISA analysis, to generally characterize the bacterial diversity among all the samples collected; ii) amplification, cloning and sequencing of archaeal 16Srrna and mcrA genes in one sample for each digester; iii) 16S profiling with the NGS approach to describe the relative abundance of phyla/genera of Bacteria and Archaea. The anaerobic biodigesters described (P1 and P2) are operating in two sites in Lombardia (Italy) separated by $200 \mathrm{~km}$ distance. Both plants were fed with cattle sewage and corn silages as substrates and operated in mesophilic regimen. P1 was followed from the startup phase up to the phase of full operation (included), while P2 was analyzed when already operative at full capacity. As for P1, a sample of the post-digester was included in the analyses.

Although several studies have studied and compared microbial communities of laboratory-scale biodigesters or full-scale digesters [5, 12, 14, 15, 19] the novelty of this study is the use of a simplified system in which two full-scale digesters, with identical technical characteristics, conducted in the same way and both fed with cattle sewage and corn biomass, derived from the respective local farms, in different seasons, were compared. It was interesting to discover that the two plants performed in very similar way despite a different phylogenetic composition of the bacterial and archaeal communities. The important finding is that an effective microbial succession developed, starting from the inoculum, and reached in both cases an optimized (although different) equilibrium of functions.

\section{Materials And Methods}

\section{Plant characteristics and management, sample collection and DNA extraction}

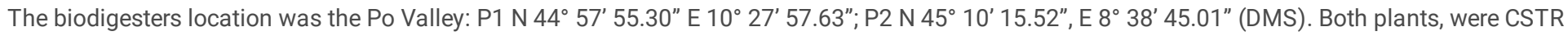
(Continuos Stirred Tank Reactor) reactors with $7200 \mathrm{~m}^{3}$ reaction volume and hydraulic retention time of 120 days. Operational parameters were monitored with online instruments: for the gas composition analysis an Awite series 7 analyzer (Await Bioenergia S.r.l Bolzano, Italy) was used; the Ultrasonic flow measuring system was Prosonic Flow 200 (Endress+Hauser Instruments International AG, Switzerland); a PT100 sensor was used to measure temperature and the portable pH 3110 (WTW-Xylem Analytics-Germany) for measuring pH. Chemical analyses were done by external laboratories (Accredia certificated) following the standard procedures: Water \& Life Lab https://www.waterlifelab.it/ and Studio Alfa-

https://www.studioalfa.it/.

Plant P1 was monitored since the start-up phase in the autumn-winter. Four phases were identified (Fig.2): I) 03 Oct-03 Nov; II) 04 Nov-5 Dec; III) 6 -18 Dec; IV) 19-31 Dec. In the phase I) the plant was loaded with a total of $1120 \mathrm{t}$ of bovine sewages. In addition, an inoculum of $540 \mathrm{t}$ of a substrate coming from a similar plant, already operative, was added on 28-29 Oct to speed up the anaerobic digestion. In the phase II) the manure amount added to biodigester was reduced and dispensed more regularly, although not daily (from $11.60 \mathrm{t} /$ day up to $84.20 \mathrm{t}$ day ${ }^{-1}$ ). From 6 Dec the average daily amount of sewage added was $20.24 \mathrm{t}$.

The corn biomass was regularly loaded into biodigester from 7 Nov, starting with $1 \mathrm{t}$, then gradually increasing until 15 Dec when $44.50 \mathrm{t}$ were loaded. The daily load of plant biomass was then regulated around 39-40 t/day. In addition, in the phase III) a vertical axis mixer was used to integrate two smaller submerged mixers. Finally, in the phase IV), the primary digester was integrated with a supporting post digester where pig manure was added. The whole process was daily monitored for temperature, $\mathrm{pH}$, VFAs, biogas production and energy cogeneration.

The P2 biodigester was started on $15 \mathrm{Mar}$, and became fully operative by $13 \mathrm{Apr}$. Since then, the average load of cattle sewage was $37.84 \mathrm{t} /$ day with corn silage varying from 19.90 to $49.20 \mathrm{t}$ /day. The collection of samples started 8 May.

Five aliquots of digestate were collected in both plants, at each specific point and stored at $-20^{\circ} \mathrm{C}$ until DNA extraction. In Table 1 are reported the data concerning VFA production $(\mathrm{mg} / \mathrm{L}), \mathrm{T}\left({ }^{\circ} \mathrm{C}\right), \mathrm{pH}$, Alkalinity $(\mathrm{mg} / \mathrm{L})$, ratio VFA/Alk, Ammonia nitrogen concentration $(\mathrm{mg} / \mathrm{Kg})$, the amount of corn silage $(\mathrm{t}$ /day) and manure ( $\mathrm{t} /$ day) added to the biodigesters, biogas production ( $\mathrm{m}^{3} /$ day), energy production (MWh/day) and are highlighted the samples used for microbial analysis.

All the samples were analyzed with ARISA (see afterwards) and only some representative samples were selected for clone libraries construction and 16S rDNA NGS profiling (Table 1).

Samples were centrifuged at $14000 \mathrm{xg}$ for $10 \mathrm{~min}$, supernatant was discarded and DNA was extracted from the pellets with FastDNA SPIN Kit for soil and FasPrep ${ }^{\circledR}$ Instrument (MP Biomedicals, Santa Ana, CA). DNA samples were checked with electrophoresis on agarose gel $0.9 \%$.

\section{PCR conditions}

All PCR were conducted with primers pairs listed in Table 2, in a mix of $25 \mu$ l containing $5 \mu$ of 1:1000 diluted DNA, 1X PCR Buffer, 200 $\mu$ M dNTPs, 100nM primers and $0.8 \mathrm{U} \mathrm{\mu l}^{-1}$ of Taq. A thermal cycler TECHNE TC-512 (Bibby Scientific Ltd, Staffordshire, UK) was used as follows: hotstart $94{ }^{\circ} \mathrm{C}$ for 
3 min, 35 cycles of denaturation $\left(94^{\circ} \mathrm{C}\right.$ for $\left.45 \mathrm{sec}\right)$, annealing $\left(58^{\circ} \mathrm{C}\right.$ for $\left.1 \mathrm{~min}\right)$ and extension $\left(72^{\circ} \mathrm{C}\right.$ for 2 min) followed by a final extension $\left(72{ }^{\circ} \mathrm{C}\right.$ for $7 \mathrm{~min})$.

The primer ReubR, for the amplification of bacterial the ITSReub, was 5'-6 FAM labelled to detect amplicons through capillary electrophoresis.

\section{ARISA (Automated Ribosomal Intergenic Spacer Analysis)}

Amplicons obtained from primers ITSF/ITSReub (Table 2) were purified with Wizard®SV Gel and PCR Clean-Up System (Promega, Madison WI, US). An aliquot of $4 \mu \mathrm{l}$ of purified DNA was mixed with $9 \mu \mathrm{l}$ of Hi-Di ${ }^{\mathrm{TM}}$ formammide (Applied Biosystems, Foster City, CA, US) and $1 \mu \mathrm{l}$ of GeneScan-2500 ROX ${ }^{\mathrm{TM}}$ Size Standard (Applied Biosystems). After denaturation at $95^{\circ} \mathrm{C}$ for 3 min and fast cooling, DNA was injected in an ABI Prism 310 (Applied Biosystems, CA, US) capillary filled with POP-4 ${ }^{\mathrm{TM}}$ Performance Optimized Polymer for electrophoresis. ARISA electropherograms were analyzed using the GeneScan 3.1 software program and elaborated with Microsoft Excel. The raw data were processed excluding the peaks whose heights and areas, proportional to the intensity of the fluorescence, were less than $1 \%$ of the sum of the same. Then the peaks were grouped according to differences of 4 bp for the fragments up to $700 \mathrm{bp}$ and $5 \mathrm{bp}$ for those up to a length of $1000 \mathrm{bp}[20,21]$. For each sample the presence (1) or absence (0) of a certain peak was determined obtaining a matrix utilised for calculation of Jaccard similarity coefficient and construction of dendrograms using the programme DendroUPGMA, available at the site http://genomes.urv.cat/UPGMA.

\section{Amplification and cloning of $16 \mathrm{~S} / m$ a and mcrA (methyl coenzyme M reductase A) genes from the archaeal community}

The DNA extracted from selected biodigesters samples (see Table 1) was diluted 1:100 and amplified with the primers, specific for Archaea, reported in Table 2 (69F and ARC934R for archaeal 16S rRNA gene and the pair mcrAF/ mcrAR for methyl coenzyme M reductase A gene for methanogenic Archaea). The amplicons obtained were purified by GFX PCR and a Gel Band Purification Kit (GE Healthcare UK Limited - HP7 9NA, UK), ligated into pGEM $^{\circledR}$-T Easy vector System I (Promega) and transformed into the strain JM109 of Escherichia coli. The recombinant colonies were subjected to colony PCR with primers SP6/T7 (Table 2) to check the presence of inserts.

\section{ARDRA (Amplified Ribosomal DNA Restriction Analysis) and sequencing}

In order to select, for sequencing, the recombinant plasmids containing fragment of 16Srrna and mcrA genes from different Archaea, the ARDRA analysis was performed respectively on 100 and 50 clones for each clone library. Restriction analysis of the cloned inserts was conducted with the enzyme Haell for $16 \mathrm{~S} r \mathrm{rn}$, and with enzymes Rsal and Alul for mcrA. $5 \mu$ l of amplified DNA was digested with $5 \mathrm{U}$ of each enzyme and $1 \mathrm{X}$ of the respective buffer at $37^{\circ} \mathrm{C}$ for $4 \mathrm{hr}$.

The restriction fragments were loaded on $2.5 \%$ NuSieve ${ }^{\circledR}$ low melting agarose gel (Lonza Group Ltd, Basel, Switzerland) on TBE buffer 0.5\% (45 mM Tris borate, $1 \mathrm{mM} \mathrm{EDTA} \mathrm{pH} \mathrm{8.0)} \mathrm{and} \mathrm{subjected} \mathrm{to} \mathrm{electrophoresis} \mathrm{at} 60 \mathrm{~V}$ for $4 \mathrm{hr}$. Images were acquired with Biorad Gel Doc 2000 and the software Quantity One (Bio-Rad, Hercules, CA, US).

One representative clone for the most represented ARDRA profiles was selected for the partial sequencing of 16Srrna gene and mcrA at BMR Genomics srl in Padova (Italy). The obtained sequences were then compared with those stored in the GenBank database at the NCBI (National Center for Biotechnology Information) by using the BLAST (Basic Local Alignment Search Tool) program (http://www.ncbi.nlm.nih.gov/blast). The sequences were deposited in GenBank (https://www.ncbi.nlm.nih.gov/genbank/) and their accession number are reported in Table 3

\section{Biodigesters microbiome profiling by 16S rRNA gene amplification and NGS sequencing}

The bacterial and archaeal community profiles of the samples were generated by NGS technologies at the Genprobio S.r.I. Laboratory. Partial 16S rRNA gene sequences of duplicate samples were obtained from the extracted DNA by Polymerase Chain Reaction (PCR), using the primer pair Probio_Uni and Probio_Rev, targeting the V3 region of the 16S rRNA gene sequence [22] for bacterial community and the primers pair ArchV56 [23] for archaeal community. Amplifications were carried out using a Verity Thermocycler (Applied Biosystems) and PCR products were purified by the magnetic purification step involving the Agencourt AMPure XP DNA purification beads (Beckman Coulter Genomics GmbH, Bernried, Germany) in order to remove primer dimers. Sequencing was performed using an Illumina MiSeq sequencer with MiSeq Reagent Kit v3 chemicals. The fastq files were processed using a custom script based on the QIIME software suite [24]. Paired-end read pairs were assembled to reconstruct the complete amplicons.

To calculate downstream diversity measures, operational taxonomic units (OTUs) were defined at 100\% sequence homology using DADA2 [25] OTUs not encompassing at least two sequences of the same sample were removed. All reads were classified to the lowest possible taxonomic rank using QIIME2 and a reference dataset from the SILVA database v132 [26]. The biodiversity of the samples (alpha-diversity) was calculated with Chao1 and Shannon indices. The $16 \mathrm{~S}$ rDNA reads were sent to GenBank to obtain their under-accession numbers. They are available as bioproject PRJNA534196.

\section{Results}

\section{Performance of the reactors}


In the plant P1, the biogas production started during phase II, after the addition of corn silage and of an inoculum coming from a similar, fully operating, plant (Fig.2). In the primary digester, the biogas production increased from $4329 \mathrm{~m}^{3} /$ day in 24 Nov up to $10.919 \mathrm{~m}^{3} /$ day in 22 Dec, with an average daily production of $7916 \mathrm{~m}^{3}$. During the entire process, the $\mathrm{pH}$ was around $7.4-7.5$, optimal values for substrate degradation and methanogenic activity and the temperature was maintained between $42.2^{\circ} \mathrm{C}$ and $44.2^{\circ} \mathrm{C}$ (average $42.8^{\circ} \mathrm{C}$ ). The concentration of volatile fatty acids (VFA) was, on average, $1643 \mathrm{mg} / \mathrm{L}$ (Table 1). At the end of December, 2 month and 20 days from startup, P1 was supported with a secondary biodigester that operated in the same condition of $\mathrm{pH}$ and temperature, but was fed with pig slurry instead of cattle slurry. The VFA concentration detected in the secondary biodigester, in $29 \mathrm{Dec}$, was lower than in primary digester $(1152 \mathrm{mg} / \mathrm{L})$. This can be explained by the dilution effect or considering that cows and pigs have different diets and the dry matter content of pigs zootechnical effluent varies from 3 to $6 \%$ (versus $8 \%-15 \%$ of cows), and has a faster biological degradability due to the lower amount of fiber.

While the P1 digester was followed and sampled from the start-up phases up to the stabilization phase, the sampling in P2 biodigester was done when the production of biogas had already stabilized.

In P2 the biogas production started at $24 \mathrm{Apr}$ and reached $8662 \mathrm{~m}^{3} /$ day by 22 May with an average value of $7796 \mathrm{~m}^{3} /$ day (comparable with P1 biodigester). The concentration of VFA was highly comparable to that of $\mathrm{P} 1$, with an average value of $1634 \mathrm{mg} / \mathrm{L}$, and also the $\mathrm{pH}$ values were similar, while the average temperature was higher $\left(44.2^{\circ} \mathrm{C}\right)$. In both plant the daily energy production was comparable in the full operational phase a sreported in Table 1 (23.90-24 MWh/ day).

\section{Bacterial community analysis by ARISA}

The Automated rRNA Intergenic Spacer Analysis (ARISA) is a molecular method for analyzing bacterial community diversity without the bias imposed by culture-based approaches. With the DNA extracted from all the samples reported in Table 1 in P1 and P2 biodigesters, ARISA profiles were obtained and compared by using a pairwise similarity coefficient, the Jaccard index. The dendrogram resulting from analysis with the programme DendroUPGMA showed that bacterial microbiome of P1 and P2 clustered in two distinct groups and, for each plant, samples were similarly grouped (Fig.3). In P1 digester one cluster encompassed samples CM2 and CM3, collected when the VFA production was almost stabilized, but the biogas production was still low; in the second cluster the communities of CM4, CM5, CM6 and CM7, collected in the phase of temperature and biogas production stabilization, were more similar and separated from CM8 when the biogas production decreased and, as expected, from CMP (the post digester). In P2, similarly, the samples clustered in two main groups one encompassing VL1 to VL6 the other encompassing VL8, VL10 and VL12, characterized by a lower VFA production and higher temperatures. ARISA does not allow description of the community in terms of bacterial genera or species, therefore, to have more detailed information, the bacterial community profiling by NGS of 16S rDNA was performed.

\section{Bacterial community $16 S$ profiling by NGS}

The bacterial community profile by NGS of 16S rDNA was determined on duplicate samples CM3, CM8 and CMP (for P1) and VL5 (for P2). MiSeq runs produced an average of 75566 sequences for the samples collected in P1 and 83931 from that collected in P2. The rarefaction curves obtained with Chao 1 and Shannon indices (a measure used to estimate the alpha diversity in samples and evaluate whether sequencing efforts allowed to capture all the microbial diversity) highlighted the lowest index of diversity in VL5. In Fig.4 (panel a) are shown only results with Shannon index. As expected, the most represented phyla in both P1 and P2 biodigesters are the Firmicutes, with similar percentages in all samples (from $62.64 \%$ to $74.54 \%$ ), followed by Bacteroidetes (14.55\% to $19.43 \%$ ) and Cloacimonetes (from 1.57\% to $8.72 \%$ ) (Fig.5).

The most represented class is that of Clostridia (between 50.50 and $61.98 \%$ ), that includes the uncultured group MBA03 (10.79\% to $21.27 \%$ ), the genus Sedimentibacter (7.93\% to $13.94 \%)$, and Clostridium sensu stricto, present at $12.29 \%$ in CM3 and in lower percentages (< $2 \%)$ in the other samples (Fig.6). The main differences between the plants P1 and P2 concern the presence of Clostridium sensu strictu, very low in VL5 (1,16\%), Hydrogenispora, (8.93\% in P2 vs $<1.5 \%$ in all samples of P1), uncultured bacterium of Lentimicrobiaceae family (9.47\% in P2 vs $<2 \%$ in all samples of $\mathrm{P} 1)$, Proteiniphilum (5.29\% in P2 vs $<1.5 \%$ in all samples of P1) and a bacterium belonging to the Bacteroidales family UCG-001 (3.10-3.58\% in P1 samples vs $<0.28 \%$ in P2). In the plant P1 is remarkable the presence of the family W27, (class Cloacimonetes) that increases from $1.15 \%$ of $\mathrm{CM} 3$ to 7.39\% in CMP and is absent in the plant P2 (Fig.6).

\section{Archaeal community analysis by cloning and sequencing of 16S rRNA genes and mcrA genes}

The first approach for archaeal community characterization was carried out trough classical molecular methods, namely the cloning and sequencing of amplified target genes. The sequences encoding partial 16S rRNA (about $870 \mathrm{bp}$ ) and part of the gene encoding methyl CoM reductase alpha subunit ( $\mathrm{mcr}$ ) gene (about $500 \mathrm{bp}$ ) were amplified from the DNA extracted from samples CM8 (in P1) and VL10 (in P2) and cloned into the vector $\mathrm{PGEM}{ }^{\circledR}$-T Easy. The cloned fragment (100 clones/gene library) were analyzed by ARDRA and generated eight reproducible profiles (A-E for P1 and F-I for P2) (Table 3). Sequence analysis of the phylotype A, representing $36 \%$ of the analyzed clones, showed $98.20 \%$ similarity with Methanotrix soehngenii (Methanosaeta) an acetoclastic archaeum. Other methanogenic species belonging to genus Methanoculleus (hydrogenotrophic and similar to Methanobacterium) as well as uncultured bacterial species were identified in P1 (Table 3) while in P2 the dominant archaeal genera were the acetoclastic, but more versatile, Methanosarcina ( $98.80 \%$ similarity with the specie thermophila) and Methanoculleus. Within these samples, several Clostridiales and other uncultured bacteria were found. This may be due to the utilization of degenerate primers amplifying also bacterial sequences very abundant in biodigesters. 
The MiSeq runs produced an average of 10912 sequences for the samples collected in P1 and 11184 from those collected in P2. Rarefaction curves obtained with Chao1 and Shannon biodiversity indices highlighted, as for bacteria, the lowest index of diversity in sample VL5 (P2) and the highest in sample CM3 (P1). In Fig.4 (panel b) are shown only the rarefaction curves obtained with Shannon index, but identical results were obtained with Chao1 biodiversity index (data not shown).

The most represented genera in both plants, are Methanobacterium, Methanosarcina, Methanosaeta, Candidatus Methanofastidiosum, Candidatus Methanoplasma, Methanobrevibacter, uncultured microorganisms of Bathyarchaeia class, and Methanoculleus (Fig.7). Methanobacterium is present in both plants, at percentages variable between $14.37-22.87 \%$ in $\mathrm{P} 1$, and $31 \%$ in $\mathrm{P} 2$.

P2 has a prevalence of Methanosarcina (49.19\%), which is present, in P1, in the samples CM3 and CMP (8.38\% and $4.62 \%$ respectively), and in very low amount in CM8 (0.73\%). This was highlighted also with the approach of cloning and sequencing the 16SrrnA and mcrA genes, previously described. P1 has a significant abundance of Methanosaeta in all samples (20\%), almost absent in P2 $(<0.05 \%)$. P1 is also characterized by the presence of $\mathrm{Ca}$. Methanofastidiosum, that increases from $10.30 \%$ in sample CM3 to $24.70 \%$ in CMP and $32.70 \%$ in CM8; while it is almost absent in P2 (0.44\%). Samples CM3 and CMP of P1 contains Methanobrevibacter ( $10.80 \%$ and $6.42 \%$, respectively), a genus strongly reduced in samples CM8 (1.45\%) and VL5 (0.39\%) of P2. Bathyarchaeia are present in samples of both plants, but in variable percentages: $19.98 \%$ in $\mathrm{CM} 3,5.44 \%$ in $\mathrm{CM} 8,2.22 \%$ in CMP and $8.88 \%$ in VL5. Methanoculleus is rather abundant in sample CM8 (4.87\%) while is less than $2.5 \%$ in the other samples. CMP is characterized by $\mathrm{Ca}$. Methanoplasma (10.05\%), absent in P2 sample and very low (<2\%) in CM3 and CM8. The sample CMP is characterized by the presence of Ca. Methanoplasma (10.05\%) absent P2 sample, and very low (<2\%) in CM3 and CM8.

\section{Discussion}

This work highlighted that two full-scale, structurally identical, biogas producing plants (P1 and P2), located in two different sites in North Italy, associated with a $999 \mathrm{~kW}$ cogeneration unit, both fed with bovine manure and corn silage, and analyzed in two different seasons, highly differ in the archaeal microbiome and, even at less extent, in bacterial microbiome, but do not differ in biogas and energy productivity.

\section{Bacterial biodiversity}

The Automated Ribosomal Intergenic Spacer Analysis (ARISA), a molecular method for analyzing bacterial community diversity without the bias imposed by the cultivation steps, showed that bacteria of P1 and P2 cluster in two distinct groups which are consistent with the operational phases (Fig.3).

The deeper analysis with NGS 16S profiling showed that bacterial populations of all samples are dominated by the phylum Firmicutes followed by Bacteroidetes. The members of these phyla have a wide metabolic capacity, including degradation of lignocellulose of corn silage and residual of bovine digestion [27]. Firmicutes are often present in fermentative plants, and in some cases, they are the most abundant bacteria [28, 29, 30]. Indeed, they possess the ability to metabolize a large variety of molecules into acetate and butyrate, VFA intermediate, and therefore they play an important role in the hydrolysis of primary substrates in anaerobic digesters. P1 was characterized by an increase in the CM8 and CMP samples of the phylum Cloacimonetes, very low in P2. Some authors suggest that members of this phylum are involved in lignocellulose degradation and play a role in the syntrophic oxidation of propionate [30,31]. The genome reconstruction of two candidates of Cloacimonetes, Candidatus Cloacimonas acidaminovorans [32] and Candidatus Syntrophosphaera thermopropionivorans [33] indicate that they possess the genes of the methylmalonylCoA pathway responsible of the oxidation of propionate. The oxidation of propionate and other short-chain fatty acids is a key step for methanogenesis to occur, as it produces acetate and $\mathrm{H}_{2}$ utilizable by both acetoclastic and hydrogenotrophic methanogens.

\section{Archaeal biodiversity}

Either cloning and sequencing of archaeal target genes and NGS archaeal 16S profiling pointed out that biodigesters P1 and P2 are characterized by the presence of Methanobacterium (14.37 to 22.87\% in samples from P1 and 31\% in P2). Methanosaeta is abundant in P1 (up to $23.05 \%$ ), while Methanosarcina is the predominant genus in P2 (49.19\%), in which Methanosaeta is almost absent. This means that, although P1 and P2 have a similar trend in biogas and VFA production and operate in the same conditions of $\mathrm{pH}$ and temperature, they must have a substantial difference in the metabolic fermentative pathways. Methanosarcina and Methanosaeta are both acetoclastic methanogens, but operate, respectively, at high and low concentration of acetate [34]. Moreover, differently from members of Methanosaeta genus, that are strictly acetoclastic, most Methanosarcina are mixotrophic, they utilize not only acetate, but also hydrogen derived from acetate oxidation conducted by anaerobic bacteria (in general Clostridia) and are able to produce methane even from methanol and methylamines. Archaea belongiong to Methanosarcina genus, in addition, are able themselves of conducting acetate oxidation, bypassing the bacterial action [35]. Differently from Methanosarcina, Methanosaeta are rather sensitive to VFA and ammonia but in this work VFA concentration does not significantly differ in P1 and P2 and ammonium concentration, even thought is different in P1 and P2, never exceeds $2000 \mathrm{mgL}^{-1}$. Therefore, the difference may be related to environmental condition of manure storage, considering that P1 started in autumn-winter, while P2 operates in spring-summer. Powell et al. (2008) observed that ammonia production and emission were significantly higher in spring than in fall-winter, not only because the temperature increases the evaporation, but also because the excreted $\mathrm{N}$ in urine is higher and urease 
activity is stimulated, producing ammonia [36, 37]. In this case the concentration of ammonium was lower in the spring/summer biodigester (P2) were Methanosarcina was the most abundant methanogen.

Karakashev et al. [35] suggest that, in the absence of Methanosaeta, the hydrogenotrophic methanogenic pathway dominated, also in presence of Methanosarcina that shifted their metabolism from acetoclastic to hydrogenotrophic methanogenesis. The same authors showed that acetate oxidation is reduced in presence of Methanosaeta. The P1 microbiome has an evolution characterized by a decrease of Methanosarcina (from 8.38 of $\mathrm{CM} 3$ to 0.73 of CM8) and by a parallel increase of Candidatus Methanofastidiosum, (formerly called WSA2 group) while Methanosaeta remains substantially unchanged. The genome analysis of $\mathrm{Ca}$. Methanofastidiosum conducted by Nobu et al.[38] revealed that this group has the peculiar capacity of producing methane through methylated thiol reduction. Moreover, members of this group may utilize acetate (as well as malonate or propionate) with $\mathrm{CO}_{2}$ as carbon source. It is possible that, in this way, they maintain low the acetate concentration favoring the growth of Methanosaeta. Our data showed a certain competition between Methanosarcina and Methanosaeta, but also between Methanosarcina and Ca. Methanofastidiosum. In general, Methanosarcina prevails over Methanosaeta because of the greater tolerance to $\mathrm{NH}_{4}{ }^{+}$, acetate and the metabolic versatility; but it is possible that $\mathrm{Ca}$. Methanofastidiosum prevails on Methanosarcina, favoring the development of Methanosaeta. The group of WAS2 was detected in different environments, like freshwater and marine sediments, contaminated groundwater and sludge biodigester [38, 39]. Recently this genus has been detected also in municipal sludge biodigester [40] and in bioreactors fed with pig manure [41] but, being uncultivable microorganism, their metabolic features were deduced only by genome analysis. However, a possible competition of WAS2 with Methanosarcinales for acetate has been hypothesized by Rivière et al. [5].

Methanobrevibacter is a typical microorganism of rumen and manure, operating a hydrogenotrophic metabolism [42]. It is present in the initial phases of biodigester activity, with fresh manure inoculum, but it is strongly reduced in the advanced phases, where it is replaced by Methanosaeta. It is almost absent in VL5 where Methanosarcina predominates. A shifting of Methanobrevibacter to Methanosarcina has been observed in another research by Ciotola et al. [43]. However, the global percentage of hydrogenotrophic Archaea remains substantially unchanged, in CM3 and CM8, as the reduction of Methanobrevibacter is compensated by an increase of Methanobacterium and Methanoculleus. The percentage of hydrogenotrophic (around 30\%) is similar also in CMP and VL5, however, in VL5 Methanobacterium is the prevalent hydrogenotrophic microorganism. The presence of acetoclastic Archaea is constant in all samples, being the increase of Methanosaeta compensated by the decrease of Methanosarcina.

In the ARISA analysis of bacterial community, the post digester of P1 (CMP) clusters separately from the samples CM4,5,6,7, as expected since it was fed with pig manure and had lower VFA concentration. Nevertheless, it seems to be closer to CM8 and this can be explained with the massive inoculum from the primary digester to the secondary digester. The lowering of VFA concentration can be the result of dilution, and the similarity of microbial communities can be ascribed to the inoculum. The NGS analysis of archaeal community indicated a similar trend, with less differences between CM8 and CMP were a predominance of Candidatus Methanofastidiosum, Methanosaeta and about 30\% of hydrogenotrophic Archaea were detected. Is rather surprising the increase of Methanosarcina to $4.62 \%$ in comparison to $0.72 \%$ of $\mathrm{CM} 8$, and a slight reduction of Methanosaeta. These results are somewhat in contrast with data reported in the literature, but according to the observation that low concentrations of VFA favor the development of Methanosaeta and not of Methanosarcina [44]- The slight reduction of Candidatus Methanofastidiosum, seems to confirm its competition with Methanosarcina. Another peculiarity of CMP is the presence of Candidatus Methananoplasma, a group of obligated hydrogen-dependent methylotrophs, but being Candidatus Methanoplasma termitium the only deeply characterised species of this group [45] it is difficult to infer its role in CMP and in methanogenesis in general.

\section{Conclusions}

In this study an integrated molecular approach was applied to analyze and compare the bacterial and archaeal communities of two full-scale Anaerobic Digestors (7200 $\mathrm{m}^{3}$ reaction volume). The two plants, identical in structure, are used for production of biogas and energy from corn silage and bovine manure and are located in Po Valley at $200 \mathrm{~km}$ distance. The plants are managed from the same company, in a comparable way. The molecular analyses were conducted from the phase of start-up to the phase of full operation in autumn-winter for P1, while P2 was analyzed when already in full activity during the spring.

It was possible to observe that, in the plant P1, there was, along four phases, a progressive stabilization of the biogas production, that reached values comparable to that of $\mathrm{P} 2$. This was accompanied by a reduction of biodiversity of bacterial and archaeal communities, thus reflecting a competition and selection of microbial populations and microbial functions. Although the plant technology, the operating characteristic, the biogas and energy production were comparable in both plants, the microbiome, in particular Archaea, resulted to be notably different. This may be linked to the different seasons in which the plants were monitored and the samples collected, but also highlights that biogas production efficiency does not necessarily depends on the phylogenetic structure of microbial community acting in AD, but rather on their optimal synergic activity. Indeed, despite the differences observed, the percentage of hydrogenotrophic methanogens remained substantially unchanged in the two plants, suggesting that this pathway is necessary. Was also interesting to observe the relevant presence of Candidatus Methanofastidiosum, an unculturable Archaeum found in extreme environment and, more recently, in some biodigesters, probably involved in methanogenesis through methylated thiol reduction. This underlines that different pathways are relevant in methane production, other than acetoclastic and hydrogenotrophic.

From the data obtained, it is possible to conclude that, in the two biogas plants, two different effective microbial succession developed independently, starting from the inoculum and reached, in both cases, an optimized (although different) equilibrium of the community, ensuring the necessary 
metabolic functions. Although the phylogenetic composition of the two communities showed important differences it appears that these microbial communities carry out similar functional processes, regardless of differences in their structure (functional similarity).

Langer et al (2015) already reached these conclusions describing the functional redundancy and structural changes of microbial communities in four lab-scale $(12 \mathrm{~L})$, continuously stirred tank reactors. The diverse microbial communities optimized their metabolism in a way that ensured efficient biogas production [44]. With the present study, conducted in full scale dimension, the same conclusion can be drawn.

\section{Declarations}

The authors declare that they have no Conflict of interest.

\section{Data Availability}

Data are available within the article. NGS and conventional sequences are available in GenBank (https://www.ncbi.nlm.nih.gov/genbank/).

\section{Funding}

This research was supported by funds to Prof. Anna Maria Sanangelantoni from FIL, of the University of Parma Local Funding for Research

\section{Author contributions}

Caterina Agrimonti: Formal analysis, Data curation, Writing- Original draft preparation

Giovanna Visioli: Validation, Writing - Review \& Editing

Anna Maria Sanangelantoni: Conceptualization, methodology, investigation, writing and reviewing.

Graziano Ferrari: Sample and data collection

\section{References}

1. Marañón, E., Salter, A.M., Castrillón, L., Heaven, S., Fernández-Nava Y.: Reducing the environmental impact of methane emissions from dairy farms by anaerobic digestion of cattle waste. Waste Manag. 31, 1745-1751 (2011)

2. Stahel, W.R.: The circular economy. Nature, 531, 435-438 (2016). doi: 10.1038/531435a.

3. Blades, L., Morgan, K., Douglas, R., Glover, S., De Rosa, M., Cromie, T., Smyth, B.: Circular Biogas-Based Economy in a Rural Agricultural Setting. Energy Procedia 123, 89-96 (2017). https://doi.org/10.1016/j.egypro.2017.07.255

4. Benato, A., Macor, A.: Italian Biogas Plants: Trend, Subsidies, Cost, Biogas Composition and Engine Emissions. Energies 12(6), 979 (2019). https://doi.org/10.3390/en12060979.

5. Rivière, D., Desvignes, V., Pelletier, E., Chaussonnerie, S., Guermazi, S., Weissenbach, J., Li, T., Camacho, P., Sghir, A.: Towards the definition of a core of microorganisms involved in anaerobic digestion of sludge. ISME J. 3, 700-714 (2009). https://doi.org 10.1038/ismej.2009.2.

6. Enzmann, F. Mayer, F., Rother, M., Holtmann. D.: Methanogens: biochemical background and biotechnological applications. AMB Express 4, 8 (2018), https://doi.org 10.1186/s13568-017-0531-x.

7. Conrad, R.: Importance of hydrogenotrophic, aceticlastic and methylotrophic methanogenesis for methane production in terrestrial, aquatic and other anoxic environments: A mini review. Pedosphere 30, 25-39 (2020). https://doi.org/10.1016/S1002-0160(18)60052-9.

8. Yekta, S.S., Ziels, R.M., Björn, A., Skyllberg, U., Ejlertsson, J., Karlsson, A., Svedlund, M., Willén, M., Svensson, B.H.: Importance of sulfide interaction with iron as regulator of the microbial community in biogas reactors and its effect on methanogenesis, volatile fatty acids turnover, and syntrophic long-chain fatty acids degradation, J.Biosci. Bioeng. 123(5), 597-605 (2017). https://doi.org/10.1016/j.jbiosc.2016.12.003.

9. Dai, X.H., Hu, C.L., Zhang, D., Dai, L.L., Duan, N.N.: Impact of a high ammonia- ammonium-pH system on methane-producing archaea and sulfatereducing bacteria in mesophilic anaerobic digestion. Bioresour. Technol. 245, 598-605 (2017), doi: 10.1016/j.biortech.2017.08.208.

10. Ziyi, Y., Wen, W., Yanfeng, H., Ruihong, Z., Guangqing, L.: Effect of ammonia on methane production, methanogenesis pathway, microbial community and reactor performance under mesophilic and thermophilic conditions. Renew. Energy 125, 915-925 (2018) https://doi.org/10.1016/j.renene.2018.03.032.

11. Raskin, L., Zheng, D., Griffin, M.E., Stroot, P.G., Misra, P.: Characterization of microbial communities in anaerobic bioreactors using molecular probes. Antonie Van Leeuwenhoek 68, 297-308 (1995). https://doi.org/10.1007/BF00874140. 
12. Krause, L., Diaz, N.N., Edwards, R.A., Gartemann, K.H., Krömeke, H., Neuweger, H., Pühler, A., Runte, K.J., Schlüter, A., Stoye, J., Szczepanowski, R., Tauch, A., Goesmann, A.: Taxonomic composition and gene content of a methane-producing microbial community isolated from a biogas reactor. J. Biotechnol. 136, 91-101 (2008),

13. Yu, Y., Lee, C., Kim, J., Hwang, S.: Group-specific primer and probe sets to detect methanogenic communities using quantitative real-time polymerase chain reaction, Biotechnol. Bioeng. 89, 670-679 (2005). https://doi.org/10.1002/bit.20347.

14. Sundberg, C., Al-Soud, W.A., Larsson, M., Alm, E., Yekta, S.S., Svensson, B.H., Sørensen, S.J., Karlsson, A.: 454 pyrosequencing analyses of bacterial and archaeal richness in 21 full-scale biogas digesters. FEMS Microbiol. Ecol., 85, 612-626 (2013). https://doi.org/10.1111/15746941.12148 .

15. Ma, S., Jiang, F., Huang, Y., Zhang, Y., Wang, S., Fan, H., Liu, B., Li, Q., Yin, L., Wang, H., Liu, H., Ren, Y., Li, S., Cheng, L., Fan, W., Deng. Y.: A microbial gene catalog of anaerobic digestion from full-scale biogas plants. Gigascience, 10 giaa164 (2021). https://doi.org/10.1093/gigascience/giaa164.

16. Luton, P.E., Wayne, J.M., Sharp, R.J., Riley, P.W.: The mcrA gene as an alternative to 16S rRNA in the phylogenetic analysis of methanogen populations in landfill. Microbiology, 148 3521-3530 (2002). https://doi.org/10.1099/00221287-148-11-3521.14 S.

17. Rastogi, G., Ranade, D.R., Yeole, T.Y., Patole, M.S. Shouche, Y.S.: Investigation of methanogen population structure in biogas reactor by molecular characterization of methyl-coenzyme M reductase A (mcrA) genes, Bioresour. Technol. 99 5317-5326 (2008).

https://doi.org/10.1016/j.biortech.2007.11.024

18. Ranjard, L., Poly, F., Lata, J.C., Mougel, C., Thioulouse, J., Nazaret, S.: Characterization of bacterial and fungal soil communities by automated ribosomal intergenic spacer analysis fingerprints. Appl. Environ. Microbiol. 67, 4479-87 (2001). https://doi.org/10.1128/aem.67.10.4479-4487.2001

19. Tao, Y., Ersahin, M.E., Ghasimi, D.S.M., Ozgun, H., Wang, H., Zhang, X., Guo, M., Yang, Y., Stuckey, D.C., van Lier, J.B.: Biogas productivity of anaerobic digestion process is governed by a core bacterial microbiota, Chem. Eng. J. 380, 122425 (2020). https://doi.org/10.1016/j.cej.2019.122425.

20. Hewson, I., Fuhrman, J.A.: Richness and diversity of bacterioplankton species along an estuarine gradient in Moreton Bay, Australia. Appl. Environ. Microbiol. 70, 3425-3433 (2004). https://doi.org/10.1128/AEM.70.6.3425.

21. Kovacs, A., Yacoby, K., Gophna, U.: A systematic assessment of automated ribosomal intergenic spacer analysis (ARISA) as a tool for estimating bacterial richness. Res. Microbiol. 161, 192-197(2010). https://doi.org/10.1016/j.resmic.2010.01.006

22. Milani, C., Hevia, A., Foroni, E., Duranti, S., Turroni, F., Lugli, G.A., Sanchez, B., Martín, R., Gueimonde, M., van Sinderen, D., et al.: Assessing the fecal microbiota: An optimized ion torrent 16S rRNA gene-based analysis protocol. PLoS ONE, 8, e68739, (2013),

https://doi.org/10.1371/journal.pone.0068739

23. Fischer, M.A., Güllert, S., Neulinger, S.C., Streit, W.R., Schmitz, R.A.: Evaluation of 16 S rRNA gene primer pairs for monitoring microbial community structures showed high reproducibility within and low comparability between datasets generated with multiple archaeal and bacterial primer pairs. Front. Microbiol. 7, 1297-1311 (2016). https://doi.org/10.3389/fmicb.2016.01297

24. Caporaso, J.G., Kuczynski, J., Stombaugh, J., Bittinger, K., Bushman, F.D., Costello, E.K., Fierer, N., Gonzalez Peña, A., Goodrich, J.K., Gordon J.I., et al.: QIIME allows analysis of high-throughput community sequencing data. Nat. Methods, 7, 335-336 (2010). https://doi.org/10.1038/nmeth.f.303.

25. Callahan, B.J., McMurdie, P.J., Rosen, M.J., Han, A.W., Johnson, A.J., Holmes, S.P.: DADA2: High-resolution sample inference from Illumina amplicon data, Nat. Methods 13, 581-583 (2016). https://doi.org/10.1038/nmeth.3869.

26. Quast, C., Pruesse, E., Yilmaz, P., Gerken, J., Schweer, T., Yarza, P., Peplies, J., Glöckner, F.O.: The SILVA ribosomal RNA gene database project: Improved data processing and web-based tools, Nucleic Acids Res. 41, D590-D596 (2013). https://doi.org/10.1093/nar/gks1219.

27. Liu, T., Sun, L., Müller, B., Schnürer, A.: Importance of inoculum source and initial community structure for biogas production from agricultural substrates. Bioresour. Technol. 245, 768-777 (2017). https://doi.org/10.1016/j.biortech.2017.08.213.

28. Cardinali-Rezende, J., Colturato, L.F.D.B., Colturato, T.D.B., Chartone-Souza, E., Nascimento, A.M.A., Sanz, J.L.: Prokaryotic diversity and dynamics in a full-scale municipal solid waste anaerobic reactor from start-up to steady-state conditions. Bioresour. Technol. 119, 373-383 (2012).

https://doi.org/10.1016/j.biortech.2012.05.136.

29. Kröber, M., Bekel, T., Diaz, N.N., Goesmann, A., Jaenicke, S., Krause, L., Miller, D., Runte, K.J., Viehöver, P., Pühler, A., Schlüter, A.: Phylogenetic characterization of a biogas plant microbial community integrating clone library 16S-rDNA sequences and metagenome sequence data obtained by 454-pyrosequencing. J. Biotechnol. 142, 38-49 (2009). https://doi.org/10.1016/j.jbiotec.2009.02.010.

30. Wei, J., Ge, T., Wah, Y.: Monitoring of microbial communities in anaerobic digestion sludge for biogas optimisation. Waste Manag. 71, 334-341 (2018). https://doi.org/10.1016/j.wasman.2017.10.007.

Page 9/17 
31. Calusinska, M., Goux, X., Fossépré, M., Muller, E.E.L., Wilmes, P., Delfosse, A.: A year of monitoring 20 mesophilic full-scale bioreactors reveals the existence of stable but different core microbiomes in bio-waste and wastewater anaerobic digestion systems, Biotechnol Biofuels. 111-19 (2018). https://doi.org/10.1186/s13068-018-1195-8.

32. Pelletier, E., Kreimeyer, A., Bocs, S., Rouy, Z., Gyapay, G., Chouari, R., Rivière, D., Ganesan, A., Daegelen, P., Sghir, A., Cohen, G.N., Médigue, C., Weissenbach, J., Le Paslier, D.: "Candidatus Cloacamonas acidaminovorans": Genome sequence reconstruction provides a first glimpse of a new bacterial division, J. Bacteriol. 190, 2572-2579 (2008). https://doi.org/10.1128/JB.01248-07.

33. Dyksma, S., Gallert, C.: Candidatus Syntrophosphaera thermopropionivorans: a novel player in syntrophic propionate oxidation during anaerobic digestion, Environ. Microbiol. Rep. 11, 558-570 (2019). https://doi.org/10.1111/1758-2229.12759.

34. Conklin, A.S., Stensel, H.D., Ferguson, J.F.: The growth kinetics and competition between Methanosarcina and Methanosaeta in mesophilic anaerobic digestion. Proc. Water Environ. Fed. 2005, 100-121(2012). https://doi.org/ 10.2175/193864705783867792.

35. Karakashev, D., Batstone, D.J., Trably, E., Angelidaki, I.: Acetate oxidation is the dominant methanogenic pathway from acetate in the absence of Methanosaetaceae. Appl. Environ. Microbiol. 72, 5138-5141 (2006). https://doi.org/10.1128/AEM.00489-06.

36. Powell, J.M., Broderick, G.A., Misselbrook, T.H.: Seasonal diet affects ammonia emissions from tie-stall dairy barns, J. Dairy Sci. $91857-869$ (2008). https://doi.org/10.3168/jds.2007-0588.

37. Minato, K., Kouda, Y., Yamakawa, M., Hara, S., Tamura, T., Osada, T.: Determination of GHG and ammonia emissions from stored dairy cattle slurry by using a floating dynamic chamber, Anim. Sci. J. 84, 165-177(2013). https://doi.org/10.1111/j.1740-0929.2012.01053.x.

38. Nobu, M.K., Narihiro, T., Kuroda, K., Mei, R., Liu, W.T.: Chasing the elusive Euryarchaeota class WSA2: Genomes reveal a uniquely fastidious methylreducing methanogen, ISME J. 10, 2478-2487 (2016). https://doi.org/10.1038/ismej.2016.33.

39. D. Wilkins, X-Y. Lu, Z. Shen, J. Chen, P.K.H. Lee, Pyrosequencing of mcrA and archaeal 16S rRNA genes reveals diversity and substrate preferences of methanogen communities in anaerobic digesters, Appl. Environ. Microbiol. 81, 604-613 (2015). https://doi.org 10.1128/aem.02566-14

40. Shakeri Yekta, S., Liu, T., Axelsson Bjerg, M., Safaric, L., Karlsson, A., Bjorg, A., Schnurer, A.: Sulfide level in municipal sludge digesters affects microbial community response to long-chain fatty acid loads, Biotechnol. Biofuels 12, 259-273 (2019). https://doi.org/10.1186/s13068-019-1598-1

41. Yang, J., Wang, D., Luo, Z., Zeng, W., Huang, H.: The role of reflux time in a leach bed reactor coupled with a methanogenic reactor for anaerobic digestion of pig manure: Reactor performance and microbial community, J. Clean Prod. 242, 118367(2020).

https://doi.org/10.1016/j.jclepro.2019.118367

42. Ozbayram, E., Ince, O., Ince, B., Harms, H., Kleinsteuber, S.: Comparison of rumen and manure microbiomes and implications for the inoculation of anaerobic digesters, Microorganisms 6, 15 (2018). https://doi.org 10.3390/microorganisms6010015.

43. Ciotola, R.J., Martin, J.F., Castańo, J.M., Lee, J., Michel, F.: Microbial community response to seasonal temperature variation in a small-scale anaerobic digester. Energies 6, 5182-5199 (2013). https://doi.org 10.3390/en6105182.

44. Wahid, R., Mulat, D.G., Gaby, J.C., Horn, S.J.: Effects of $\mathrm{H}_{2}: \mathrm{CO}_{2}$ ratio and $\mathrm{H}_{2}$ supply fluctuation on methane content and microbial community composition during in-situ biological biogas upgrading. Biotechnol Biofuels 12, 104 (2019), https://doi.org/10.1186/s13068-019-1443-6.

45. Lang, K., Schuldes, J., Klingl, A., Poehlein, A., Daniel, R., Brune, A.: New mode of energy metabolism in the seventh order of methanogens as revealed by comparative genome analysis of "Candidatus Methanoplasma termitum”, Appl. Environ. Microbiol. 81, 1338-1352 (2015).

https://doi.org/10.1128/AEM.03389-14

46. Langer, S.G., Ahmed, S., Einfalt, D., Bengelsdorf, F.R., Kazda, M.: Functionally redundant but dissimilar microbial communities within biogas reactors treating maize silage in co-fermentation with sugar beet silage. Microb. Biotechnol. 8, 828-836 (2015)

47. Cardinale, M., Brusetti, L., Quatrini, P., Borin, S., Puglia, A.M., Rizzi, A., Zanardini, E., Sorlini, C., Corselli, C., Daffonchio, D.: Comparison of different primer sets for use in automated ribosomal intergenic spacer analysis of complex bacterial communities. Appl. Environ. Microbiol. 70, $6147-6156$ (2004). https://doi.org/10.1128/AEM.70.10.6147-6156.2004

48. Klocke, M., Nettmann, E., Bergmann, I., Mundt, K., Souidi, K., Mumme, J., Linke, B.: Characterization of the methanogenic Archaea within two-phase biogasreactor systems operated with plant biomass. Syst. Appl. Microbiol. 31, 190-205 (2008). https://doi.org/10.1016/j.syapm.2008.02.003

\section{Tables}

Table 1. Samples collected in the biodigesters P1 (CM2 to CMP) and P2 (VL1 to VL12), respective operating conditions, VFA, biogas and energy production. Samples CM3, CM8, CMP and VL5 (in bold characters) were used for NGS analysis and CM8*and VL10 (bold italic) for cloning and 
sequencing of archaeal sequences. n.r. Not reported.

\begin{tabular}{|c|c|c|c|c|c|c|c|c|c|c|c|c|}
\hline \multirow[b]{2}{*}{ Sample } & \multirow[b]{2}{*}{$\begin{array}{l}\text { Sampling } \\
\text { site }\end{array}$} & \multirow[b]{2}{*}{$\begin{array}{l}\text { Time of } \\
\text { collection }\end{array}$} & \multirow[b]{2}{*}{$\begin{array}{l}\text { VFA } \\
\left(\mathrm{mgL}^{-1}\right)\end{array}$} & \multirow[b]{2}{*}{$\mathrm{T}^{\circ} \mathrm{C}$} & \multirow[b]{2}{*}{$\mathrm{pH}$} & \multirow[b]{2}{*}{$\begin{array}{l}\text { Alkalinity } \\
\left(\mathrm{mgL}^{-1}\right)\end{array}$} & \multirow[b]{2}{*}{$\begin{array}{l}\text { Ratio } \\
\text { VFAVAlk }\end{array}$} & \multirow[b]{2}{*}{$\begin{array}{l}\text { Ammonia } \\
\text { nitrogen } \\
\text { concentration } \\
\left(\mathrm{mg} \mathrm{Kg}^{-1}\right)\end{array}$} & \multicolumn{2}{|c|}{ Feeding } & \multicolumn{2}{|c|}{ Production } \\
\hline & & & & & & & & & $\begin{array}{l}\text { Com } \\
\text { silage } \\
(\mathrm{t} \\
\left.\text { day }^{-1}\right)\end{array}$ & $\begin{array}{l}\text { Manure } \\
\text { (t day } \\
\text { 1) }\end{array}$ & $\begin{array}{l}\text { Biogas } \\
\left(\mathrm{m}^{3}\right. \\
\left.\text { day }^{-1}\right)\end{array}$ & $\begin{array}{l}\text { Energy } \\
\text { (MWh day } \\
\text { 1) }\end{array}$ \\
\hline $\mathrm{CM} 2$ & $\begin{array}{l}\text { Primary } \\
\text { digester }\end{array}$ & $17 \mathrm{Nov}$ & 1784 & 42.2 & 7.51 & 15840 & 0.11 & & 8.90 & 54.80 & 2486 & 0 \\
\hline CM3 & $\begin{array}{l}\text { Primary } \\
\text { digester }\end{array}$ & 24 Nov & 1689 & 42.5 & 7.46 & 14325 & 0.12 & 1875 & 21.70 & 0 & 4329 & 0 \\
\hline CM4 & $\begin{array}{l}\text { Primary } \\
\text { digester }\end{array}$ & $01 \mathrm{Dec}$ & 1677 & 43.1 & 7.46 & 13699 & 0.12 & & 33.80 & 0 & 6703 & 0.7 \\
\hline CM5 & $\begin{array}{l}\text { Primary } \\
\text { digester }\end{array}$ & $08 \mathrm{Dec}$ & 1766 & 43.3 & 7.47 & 13598 & 0.13 & & 41.40 & 0 & 8259 & 17.70 \\
\hline CM6 & $\begin{array}{l}\text { Primary } \\
\text { digester }\end{array}$ & $15 \mathrm{Dec}$ & 1834 & 43.1 & 7.48 & 13334 & 0.14 & 1951 & 44.50 & 20.20 & 9140 & 24 \\
\hline CM7 & $\begin{array}{l}\text { Primary } \\
\text { digester }\end{array}$ & $22 \mathrm{Dec}$ & 1463 & 44.2 & 7.44 & 12663 & 0.12 & & 40.70 & 16.90 & 10919 & 24 \\
\hline CM8 & $\begin{array}{l}\text { Primary } \\
\text { digester }\end{array}$ & $26 \mathrm{Dec}$ & 1804 & 42.5 & 7.49 & 12464 & 0.14 & & 39.10 & 17.80 & 8031 & 24 \\
\hline CM8* & $\begin{array}{l}\text { Primary } \\
\text { digester }\end{array}$ & $26 \mathrm{Dec}$ & 1804 & 42.5 & 7.49 & 12464 & 0.14 & & 39.10 & 17.80 & 8031 & 24 \\
\hline CMP & $\begin{array}{l}\text { Post } \\
\text { digester }\end{array}$ & $29 \mathrm{dec}$ & 1152 & 41.5 & 7.67 & 14145 & 0.13 & & n.r. & n.r. & n.r. & \\
\hline VL1 & $\begin{array}{l}\text { Primary } \\
\text { digester }\end{array}$ & 08 May & 1790 & 40.9 & 7.33 & 10968 & 0.16 & 1100 & 39.70 & 0 & 7920 & 22 \\
\hline VL2 & $\begin{array}{l}\text { Primary } \\
\text { digester }\end{array}$ & 15 May & 1783 & 42.2 & 7.43 & 9855 & 0.18 & & 41.00 & 0 & 8180 & 23.90 \\
\hline VL3 & $\begin{array}{l}\text { Primary } \\
\text { digester }\end{array}$ & 22 May & 1379 & 42.5 & 7.35 & 9423 & 0.15 & & 41.80 & 24.90 & 8662 & 23.20 \\
\hline VL4 & $\begin{array}{l}\text { Primary } \\
\text { digester }\end{array}$ & 29 May & 1751 & 41.7 & 7.45 & 8499 & 0.21 & & 32.20 & 49.20 & 6737 & 23.90 \\
\hline VL5 & $\begin{array}{l}\text { Primary } \\
\text { digester }\end{array}$ & 5 June & 1844 & 42.8 & 7.51 & 8974 & 0.21 & 1315 & 36.70 & 19.90 & 7637 & 23 \\
\hline VL6 & $\begin{array}{l}\text { Primary } \\
\text { digester }\end{array}$ & 12 June & 1776 & 44.3 & 7.50 & 8835 & 0.20 & & 37.30 & 20.30 & 8159 & 23.90 \\
\hline VL8 & $\begin{array}{l}\text { Primary } \\
\text { digester }\end{array}$ & 19 June & 1367 & 46.9 & 7.50 & 8711 & 0.16 & & 36.00 & 27.00 & 7538 & 23.90 \\
\hline$V L 10$ & $\begin{array}{l}\text { Primary } \\
\text { digester }\end{array}$ & 26 June & 1434 & 47.9 & 7.51 & 9021 & 0.16 & & 36.00 & 27.00 & 7690 & 24 \\
\hline VL12 & $\begin{array}{l}\text { Primary } \\
\text { digester }\end{array}$ & 03 July & 1403 & 47.7 & 7.53 & 9504 & 0.15 & 1320 & 39.90 & 27.10 & 7642 & 24 \\
\hline
\end{tabular}

Table 2. Primers utilised in this study. "Y", "R" "M" and "W" mean degenerate bases. 


\begin{tabular}{llll} 
Primer & Sequence & Ta $\left({ }^{\circ} \mathrm{C}\right)$ & Ref. \\
\hline ITSF & 5'-GTCGTAACAAGGTAGCCGTA-3' & 58 & {$[47]$} \\
ITSReub & 5'-GCCAAGGCATCCACC-3' & & \\
\hline & 5'-YGAYTAAGCCATGCRAGT-3' & 47 & {$[48]$} \\
69F & 5'-TGCTCCCCCGCCAATTCCT-3' & & \\
ARC934R & & & \\
\hline & 5'-TATTTAGGTGACACTATAG-3' & 50 & \\
SP6 & 5'-TAATACGACTCACTATAGGG-3' & & \\
T7 & & & \\
\hline \multicolumn{5}{l}{ 5'-GGTGGTGTMGGATTCACARTATGCW-3' } & 55 & \\
mcrAR & 5'-TTCATTGCRTAGTTWGGRTAGTT-3' & &
\end{tabular}

Table 3. ARDRA profiles detected after restriction analysis of amplicons derived from rRNA 16S of Archaea, their relative abundance in the analysed clones and similarity with bacteria species established with BLAST analysis.

\begin{tabular}{|c|c|c|c|c|}
\hline $\begin{array}{l}\text { Profiles P1 (Accession } \\
\text { number) }\end{array}$ & $\begin{array}{l}\text { Relative abundance in } \\
\text { P1 }\end{array}$ & Similar microorganism (Accession number) & $\begin{array}{l}\text { Sequence } \\
\text { similarity }\end{array}$ & Functional group \\
\hline 16S A (CM8) (MW381770) & $36 \%$ & Methanothrix soehngenii (NR_104707.1) & $98.20 \%$ & Acetoclastic \\
\hline 16S B (CM8) (MW381771) & $17 \%$ & Methanoculleus bourgensis (NR_114489.1) & $98.07 \%$ & Hydrogenotrophic \\
\hline 16S C (CM8) & $6 \%$ & Uncultured bacterium (FJ205838.1) & $73 \%$ & \\
\hline 16S D (CM8) & $8 \%$ & Uncultured bacterium (JX102010.1) & $96.85 \%$ & \\
\hline 16S E (CM8) (MW381772) & $6 \%$ & Methanoculleus bourgensis (AB065298.1) & $98.68 \%$ & Hydrogenotrophic \\
\hline 16S mix (CM8) & $27 \%$ & Unidentified miscellaneus clones & & \\
\hline 16S F (VL10) (MW381773) & $32 \%$ & Methanosarcina thermophila (NR_044725.1) & $98.8 \%$ & Acetoclastic \\
\hline 16S G (VL10) (MW381774) & $25 \%$ & $\begin{array}{l}\text { Methanoculleus hydrogenitrophicus (NR } \\
\text { 116881.1) }\end{array}$ & $99.52 \%$ & Hydrogenotrophic \\
\hline 16S I (VL10) (MW381775) & $10 \%$ & Hydrogenispora ethanolica (NR_125455.1) & $90.22 \%$ & \\
\hline 16S mix (VL10) & $33 \%$ & Unidentified miscellaneus clones & & \\
\hline
\end{tabular}

\begin{tabular}{|c|c|c|c|}
\hline Profiles P1 (Accession number) & Similar microorganism (Accession number) & Sequence similarity & Functional group \\
\hline Mcr1 (CM8) (MW390769) & Uncultured methanogenic archeon (JQ686784.1) & $98.92 \%$ & \\
\hline Mcr2 (CM8) (MW390770) & Uncultured methanogenic archeon (JQ686770.1) & $99 \%$ & \\
\hline Mcr3 (CM8) (MW390771) & Uncultured methanogenic archeon (AB615638.1) & $99.15 \%$ & \\
\hline Mcr4 (CM8) (MW390772) & Uncultured Methanobacterium sp (KJ487752.1) & $98 \%$ & Hydrogenotrophic \\
\hline Profiles P2 (Accession number) & Similar microorganism (Accession number) & Sequence similarity & Functional group \\
\hline Mcr5 (VL10) (MW390773) & Methanoculleus bourgensis (LT549891.1) & $98,76 \%$ & Hydrogenotrophic \\
\hline Mcr6 (VL10) (MW390774) & Methanosarcina flavescens (СР032683.1) & $97.54 \%$ & Acetoclastic \\
\hline Mcr7 (VL10) (MW390775) & Uncultured methanogenic archeon (EF628139.1) & $99 \%$ & \\
\hline Mcr8 (VL10) (MW390776) & Methanosarcina thermophila (AB353225.1) & $98.30 \%$ & Acetoclastic \\
\hline
\end{tabular}

\section{Figures}




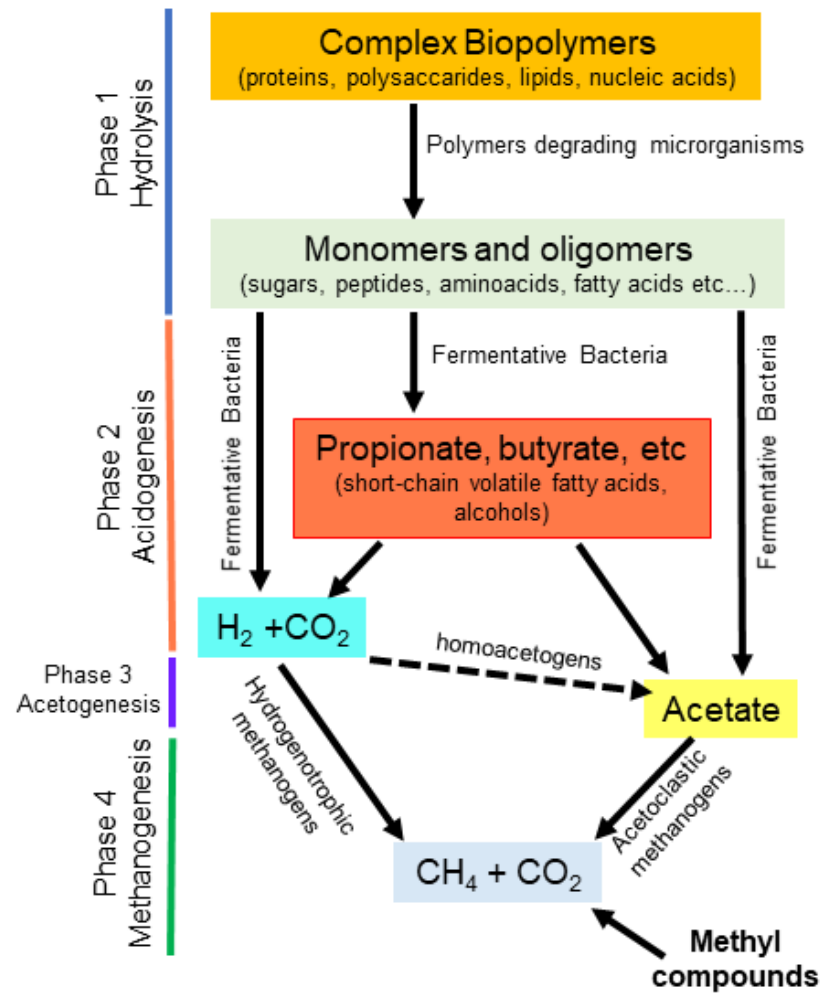

Figure 1

The key stages of anaerobic digestion process, schematically represented.

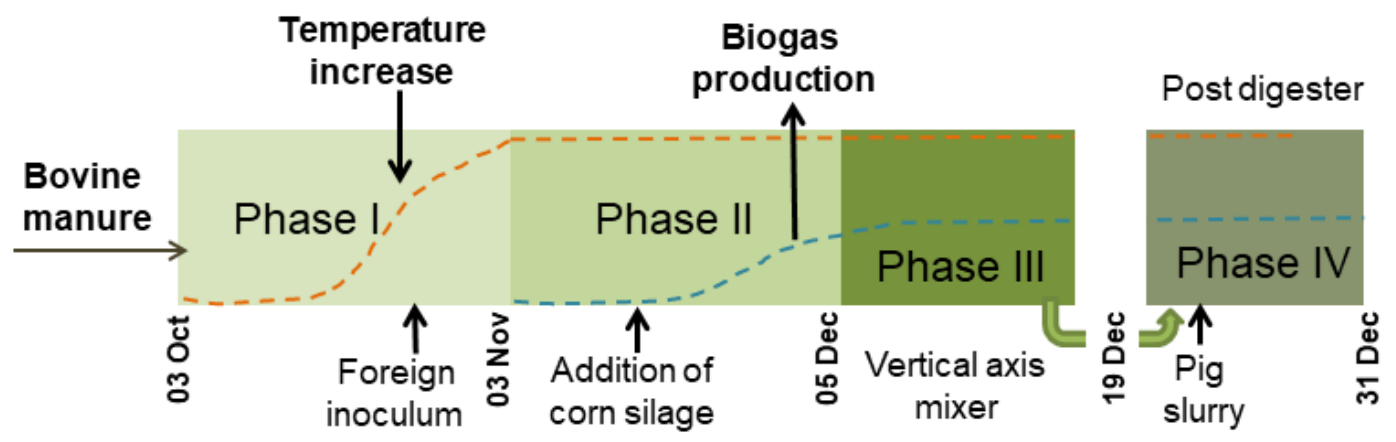

Figure 2

Synoptic diagram of the start-up phases of P1. 


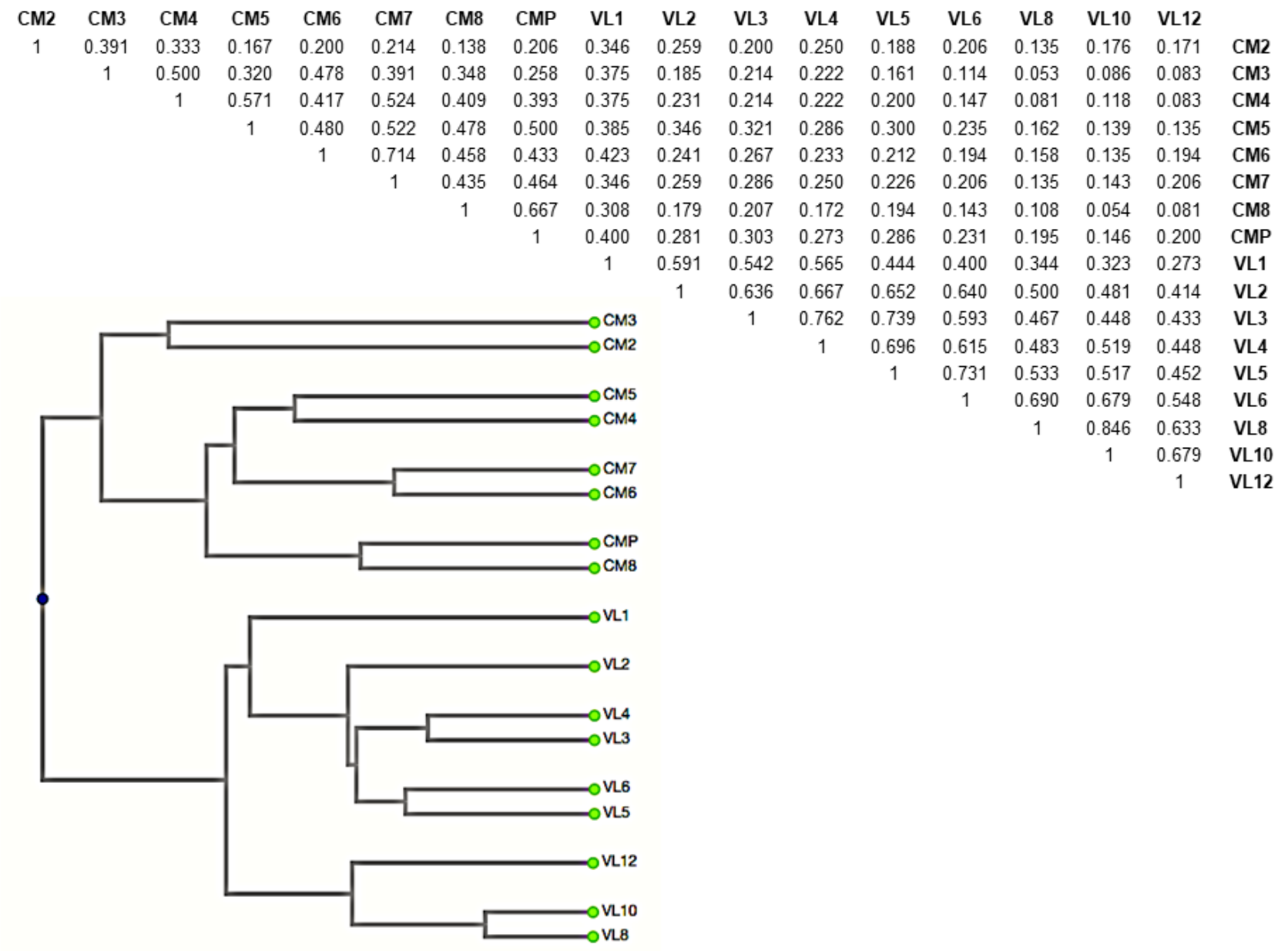

Figure 3

UPGMA dendrogram of P1 and P2 obtained from ARISA profiles. 

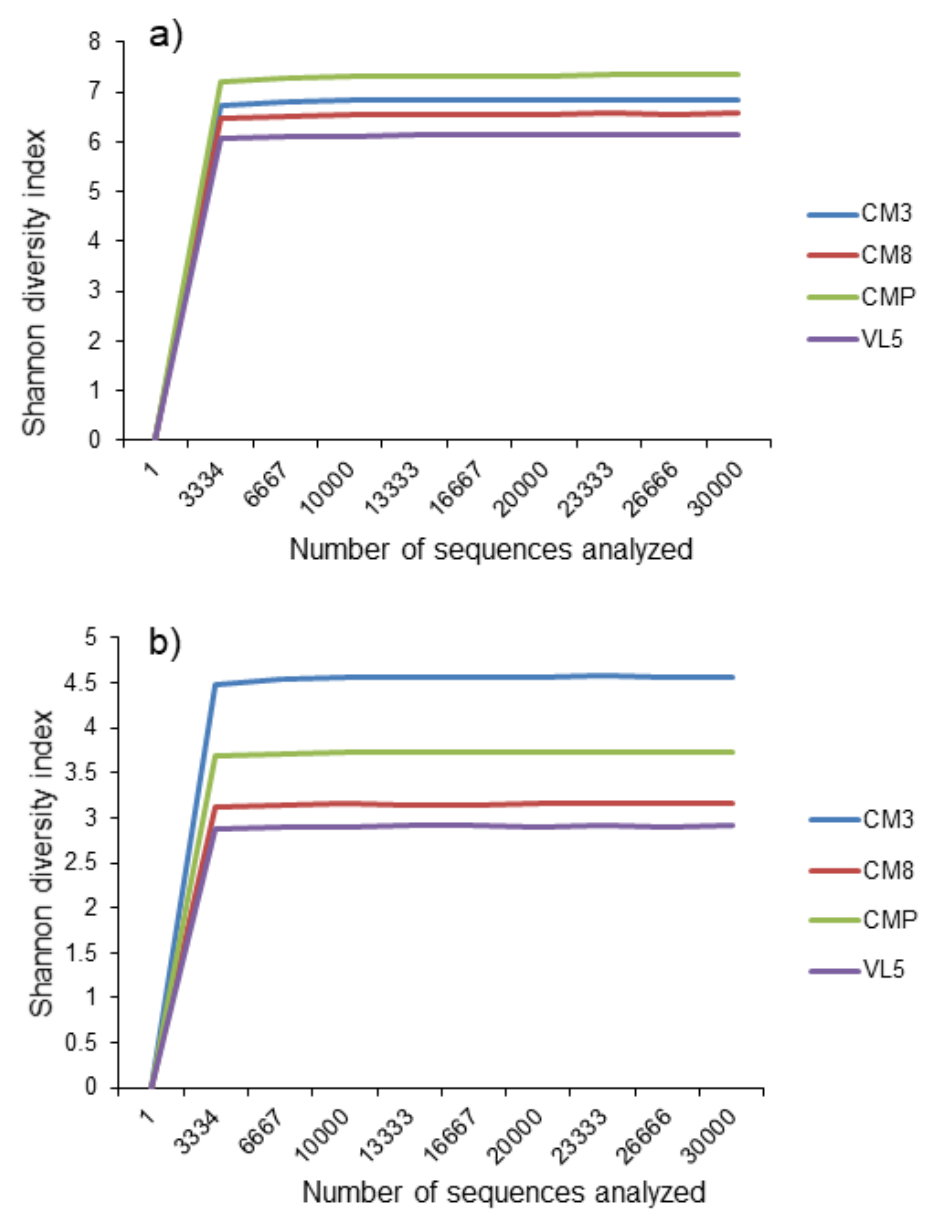

\section{Figure 4}

Rarefaction curves derived by Shannon diversity index of Bacteria (a) and Archaea (b) of samples CM3, CM8, CMP and VL5 calculated on the basis of $16 S$ rDNA NGS taxonomy profiling.

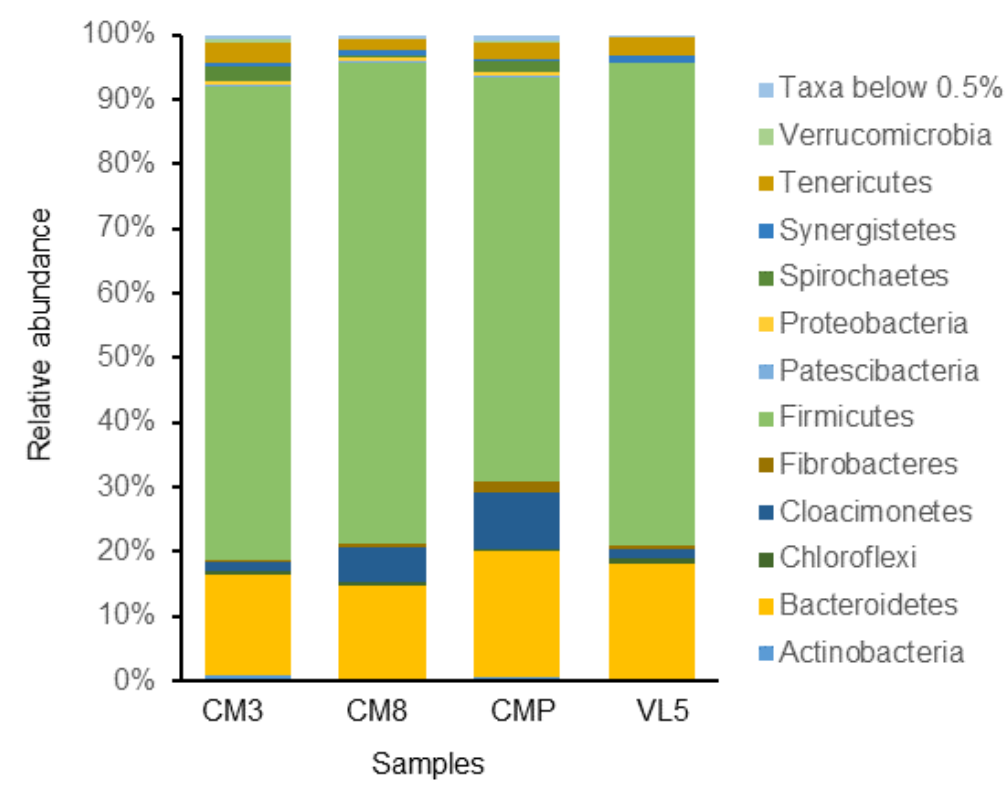

Figure 5 
Relative abundance of bacterial phyla in the samples CM3, CM8, CMP and VL5 calculated through 16S rDNA NGS taxonomy profiling (average of duplicated biological samples).
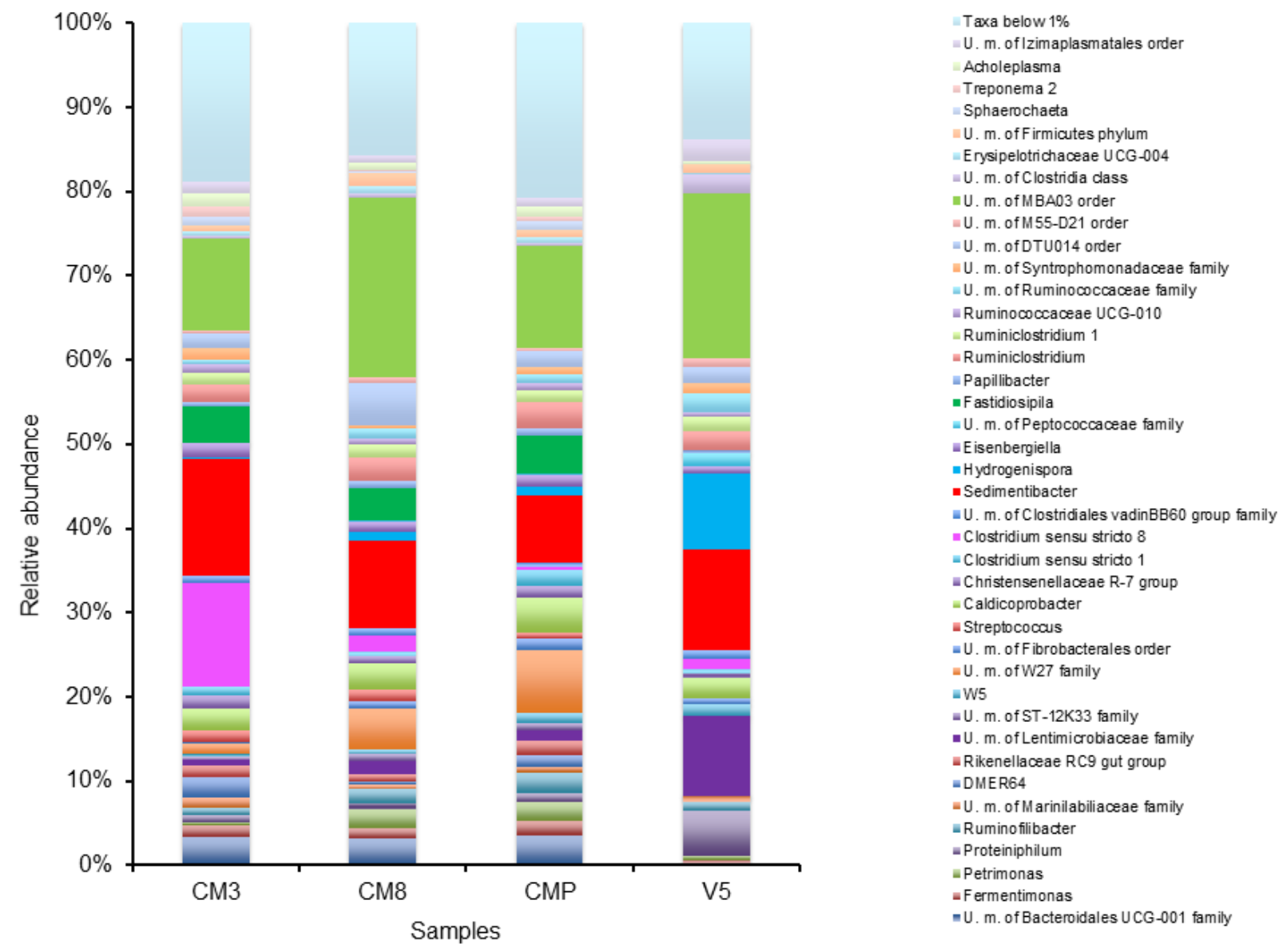

\section{Figure 6}

Relative abundance of bacterial genera (> 1\%) in the samples CM3, CM8, CMP and VL5 calculated through 16S rDNA NGS taxonomy profiling (average of duplicated biological samples). 


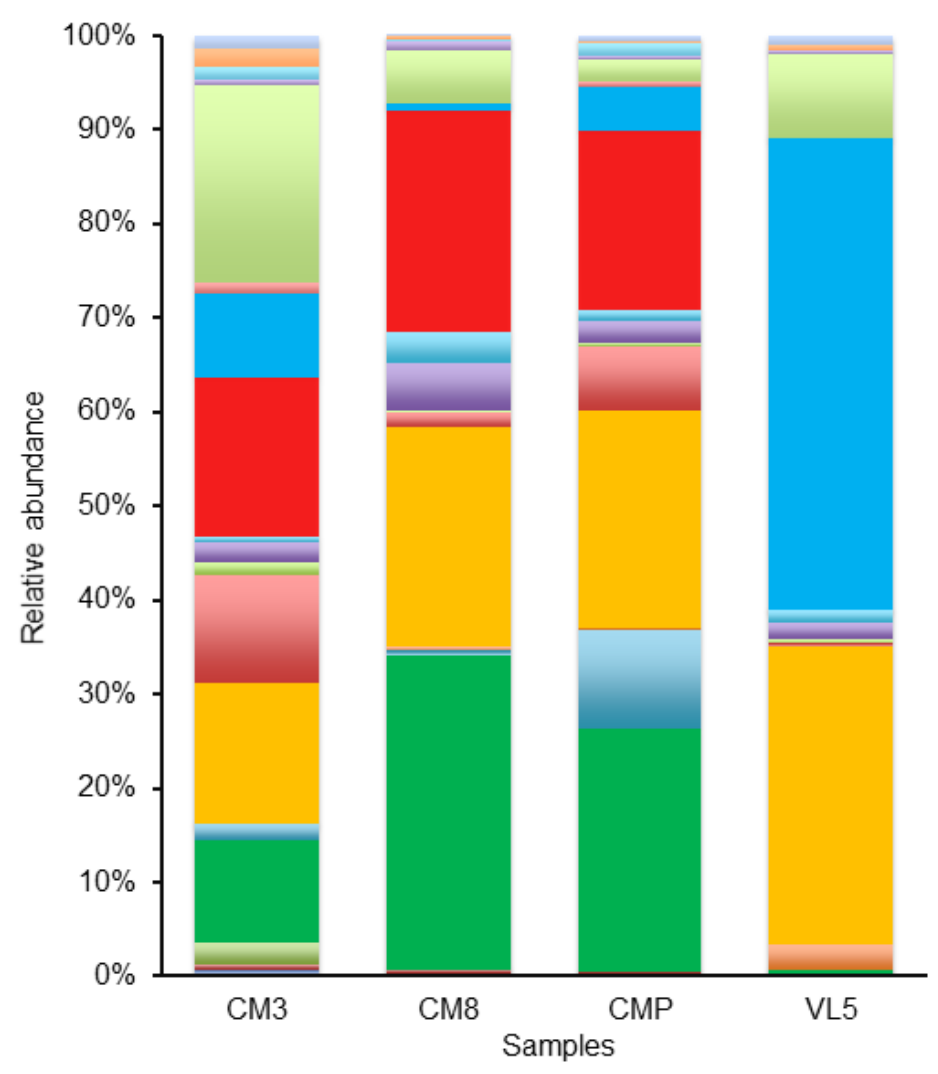

- U. m. of Woesearchaeia class

U. m. of Syntrophomonadaceae family

घ U. m. of M ethanomethylophilaceae family

$=\mathrm{U} . \mathrm{m}$. of MBA03 order

- U. m. of Bathyarchaeia class

- Methanosphaera

- Methanosarcina

- Methanosaeta

- Methanomassiliicoccus

- Methanoculleus

- Methanocorpusculum

- Methanobrevibacter

n Methanobacterium

= Hydrogenispora

= Candidatus M ethanoplasma

- Candidatus M ethanofastidiosum

- Brevundimonas

abelow $1 \%$

- Acidipila

\section{Figure 7}

Relative abundance of archaeal genera (> 1\%) in the samples CM3, CM8, CMP and VL5 calculated through 16S rDNA NGS taxonomy profiling (average of duplicated biological samples).

\section{Supplementary Files}

This is a list of supplementary files associated with this preprint. Click to download.

- Graphicalabstract.pptx 